\title{
UC Merced STEM Resource Center: Program Development, Assessment and Improvements
}

\author{
${ }^{1}$ Petia Gueorguieva, ${ }^{2}$ Amy Moffat \\ ${ }^{1}$ University of California Merced, ${ }^{2}$ Humboldt State University \\ USA
}

\begin{abstract}
Established in Fall 2013 at the University of California (UC) Merced, the Science, Technology, Engineering, and Math (STEM) Resource Center's mission is to provide academic and extra-curricular support for undergraduate students majoring in the STEM disciplines, support faculty, and lead $K-12$ (primary and secondary education) outreach initiatives. The main objective of this paper is to discuss the STEM Center's program development and validate the impact it has on the UC Merced undergraduate students and the Merced K-12 STEM community. We present assessment processes and improvements, the construction of a Logic Model, and the implementation of an effective Assessment Plan. Such combination of a logic model with the assessment cycle is unique to UC Merced and cutting edge in the assessment field. We discuss topics applicable on global educational scale, such as positive effects of a supportive STEM-learning community and the importance of units' teamwork in bringing university resources to a diverse body of undergraduate students.
\end{abstract}

\section{Introduction}

University of California (UC) Merced is located in the city of Merced, the heart of California's Central Valley, generally viewed as an economically disadvantaged region [1]. UC Merced opened its doors to students in Fall 2005 as the first research university in the U.S. in the twenty-first century. UC Merced currently serves more than 8,000 undergraduate students of whom 58 percent are STEM majors. As a higher education institution, it is a Minority and Hispanic Serving Institution (MSI and HSI) with 73 percent first generation, 64 percent Pell Grant (financial aid for low-income students), and 61 percent are from underrepresented groups [2]. Having in mind the cultural and ethnical diversity of UC Merced's undergraduate body and the fact that participation of minorities and women in the STEM field is underrepresented on global level $[3,4,5]$, we are motivated to share our results and best practices with international higher education professionals. We present the positive impacts of a supportive STEM-learning community and the importance of units' teamwork in bringing university resources to students, which are topics applicable on the global education scale. The main goal of this article is to discuss the STEM Center's program development and validate the impact it has on the UC Merced undergraduate student body and the Merced K-12 (primary and secondary education) STEM community.

\section{STEM Resource Center: program development}

\subsection{Overview}

Established in Fall 2013 at UC Merced, the Science, Technology, Engineering, and Math (STEM) Resource Center is a designated nonclassroom undergraduate STEM student-centered learning community on campus, where students from various STEM majors and levels gather and network. The STEM Center's objective is to provide academic and extra-curricular support for undergraduate students majoring in the STEM disciplines, support faculty, and lead K-12 outreach initiatives. The STEM Center's mission is to guide students to flourish in their intellectual endeavors through assisting them in uncovering academic and research opportunities and acknowledge personal responsibility for their own success. To fulfill its purpose and best serve UC Merced's undergraduate population, the STEM Center developed its service goals through collaborative work with UC Merced's assessment offices, student success units, faculty, and academic advisors.

Assessment practices take a major part in evaluating the above work. With the purpose of implementing structured evaluation and improve validation processes, the STEM Center constructed an effective Assessment Plan and a Program Logic Model. The STEM Center is one of the first at UC Merced to incorporate a logic model with its assessment cycle, which is a cutting-edge practice in the assessment field. To attain meaningful evaluation of the STEM Center's service goals and corresponding outcomes outlined in its Assessment Plan, a combination of direct and indirect assessment methods is applied. Metric data, such as physical location usage, semester grade analysis, and GPA comparison, is collected to evaluate service strategies and results achieved upon their application. 


\subsection{Program specifics and student services}

The STEM Resource Center provides academic support to the UC Merced undergraduate student population through a variety of services aimed at supporting academics and learning. In addition, it leverages the UC Merced investment by pursuing external funding through collaboration with faculty on large-scale institutional proposals. Educational and undergraduate research components are an essential part of research grants, therefore the STEM Center provides support for grant writing and implementation of obtained funding. Via collaborative work with faculty and administrators, the STEM Center supports UC Merced's undergraduate scholarship programs funded through NASA and the National Science Foundation, coordinates the logistics of these paid programs, and recruits' students for faculty-led undergraduate research projects.

The services the STEM center provides, are grouped in three major areas: 1. Academic Support Peer-Tutor/Mentor Program; 2. Undergraduate Research; and 3. K-12 Outreach. Each area is discussed below.

\subsubsection{Academic Support - Peer-Tutor/Mentor} Program. The STEM Center provides a physical location for undergraduate students from different STEM majors to study and interact. The Peer Tutor/Mentor Program was established within the STEM Center with the objective of providing academic assistance to undergraduate students, thus contributing to UC Merced's goal of increasing undergraduate retention rates in math, science and engineering disciplines. The program was designed to serve the diverse UC Merced undergraduate population by delivering continuous and comprehensive educational support to any student currently enrolled in a program supported course, in the form of peer-tutoring and mentoring. The PeerTutor/Mentor Program aims to enable students to enrich their educational experiences in the STEM field and perform at high levels in their courses. Peer-tutors/mentors volunteer their time, unless external funding is obtained, and engage students in learning activities to improve their knowledge in a specific subject and to enhance study skills development. For students' convenience, help is provided on walk-in basis and no appointments are necessary. Most peer-tutor sessions are One-On-One with the peer-tutor, but Small Group sessions are sometimes offered, based on demand.

In addition to serving the UC Merced student body, the Peer-Tutor/Mentor Program aims to reinforce peer-tutors/mentors' conceptual knowledge and enrich their professional skills and intellectual experiences. With the purpose of increasing peertutors/mentors' understanding of diversity sensitivity and best practices and behaviors in working with peers, a Professional Development (PD) Workshop series was created. Led by the STEM Center, the Professional Development (PD) workshop series is a collaborative student-learning initiative offered to all peer-driven learning and mentoring units at UC Merced. The objective of the PD series is to enhance peer-tutors and mentors' knowledge on the pedagogical and mentoring aspects of working with a diverse population of students having varied backgrounds. The workshops are facilitated by UC Merced professionals and students are awarded a Certificate of Achievement upon completion of the series.

\subsubsection{Undergraduate research. Students'} coursework understanding is reinforced and more completely assimilated when they are given the opportunity to apply that knowledge outside of the classroom and studies indicate that participation in research improves students' abilities to comprehend fundamental concepts across academic disciplines [6, 7]. New case studies also demonstrate the positive impact of participation in a research experience for undergraduates (REU) program not only on students from underrepresented groups, but, more generally, on any student with limited access to research opportunities [8]. Research invariably leads to a better understanding of and a deeper appreciation for the discipline under investigation. Studies demonstrate that the "undergraduate experience is greatly enriched by attaining research experience early and often" [5]. Literature also suggests that low participation of students from underrepresented groups in the STEM fields is a result of low selfconfidence and lack of understanding of how society benefits from science [5, 9-11].

Additionally, participation in research engages students' in applying their knowledge outside of the classroom and is a significant confidence booster. Students' career goals are typically clarified after they participate in research, which is especially true when a caring faculty member guides the student. Research activities help make undergraduates more comparative and their résumés more attractive to graduate school, professional schools and future employers. For these reasons, the STEM Center strongly encourages student participate in undergraduate research via introducing them to the importance of research work and to specific scholarship opportunities.

2.2.3. K - 12 Outreach. The STEM Resource Center contributes to the building of a strong connection between UC Merced and the wider California Central Valley communities, such as higher education institutions, local schools, and organizations interested in the STEM education field. The STEM Center makes every effort to help in the 
organization and implementation of on- and offcampus outreach events which promote STEM disciplines and introduce UC Merced to groups of students who are our potential undergraduate and graduate candidates. The STEM Center had established collaborations with local K-12 schools, contributes to the implementation of STEM programs at these sites, and promotes UC Merced research activities in the community. Via demonstrations, lessons and hands-on activities held at local schools and science fairs, UC Merced undergraduate students and staff provide academic enrichment and STEM learning opportunities for the San Joaquin Valley K - 12 students.

\section{STEM Resource Center: program assessment}

\subsection{Processes and methods}

In order to evaluate its work and effectiveness of services offered to students, the STEM Center uses direct and indirect assessment methods to collect and analyze student data. Data on the specific usage of the STEM Center's physical location is collected via UC Merced's electronic ID card check-in system. Peer-tutors/mentors record the number of students they serve, the courses they help with, and the mentoring suggestions they provide. To monitor students' academic progress to the extent possible, the STEM Center collects metric data related to student's grades in a particular course for students who used peer-tutoring services and compares these to the average class performance. Additionally, for selected student programs, data on participants' overall GPA is collected and compared with data for students in similar academic standing. For STEM Center-supported UC Merced undergraduate programs, data is collected on participants' academic performance and on graduate school and job placements for graduating seniors. Analyzing these metric data serves as a direct assessment method and provides valuable insights on the usefulness of the provided services. The STEM Center uses surveys as an indirect assessment method. Surveys are administered each semester in collaboration with UC Merced's School of Natural Sciences (SNS) Assessment Office and Student Assessing Teaching and Learning (SATAL) unit. External program evaluators collect feedback from students participating in undergraduate research programs.

Each academic year, we overcome specific assessment challenges related to STEM Center's assessment and evaluation. The center is open to provide services to all UC Merced students and, unlike students participating in pre-set programs, these students are not held accountable to report back on their progress. This makes tracking student academic and research participation data difficult and leads to incomplete results. Successful attempts to overcome this challenge were made by asking students to participate in confidential (but not anonymous) surveys and report their academic results to us. By following Family Education Rights and Privacy Act (FERPA) requirements and keeping student data strictly confidential at all items, information is shared between UC Merced partners such as Engineering Service Learning, Undergraduate Research Opportunity Center, and the Center for Career and Professional Advancement. Furthermore, as described above (section 2.2), the STEM Center supports multiple areas of work, thus each area is assessed separately, according to its own criteria, which enormously increases the amount of evaluation analyses performed by professional staff. Therefore, to address such issues and fully evaluate its work, after two years of serving UC Merced's student body, in Fall 2015, the STEM Center applied a more systematic approach and made significant improvements to its assessment strategies.

\subsection{Improvements}

Assessment plan and corresponding goals: The STEM Center's Assessment Plan was created to provide a comprehensive approach in evaluating center's assessment goals. The plan was developed in collaboration with SNS Assessment Office and in accordance with UC Merced's assessment policies set by the campus, and administered by the Office of Periodic Reviews, Assessment, and Accreditation Support. Our Assessment Plan lists service goals grouped in the following four areas:

1. Academic Support for Undergraduate Students;

2. Undergraduate Research and Fellowship Opportunities;

3. K-12 STEM Outreach Collaborations; and

4. Grants and External Funding Opportunities.

To ensure a more metric-oriented measure for an in-depth evaluation, specific outcomes are set for each goal. Goals are assessed yearly, according to their own benchmarks and criteria.

Logic Model: At UC Merced, we have used a Logic Model as an assessment tool, by marrying the Kellogg Foundation's logic model [12] with the traditional higher education assessment cycle. For a program that has a clear intervention on student learning, such as peer-tutoring, the logic model is a visual tool to see how certain activities (the intervention) can be connected to student learning outcomes and eventually contribute to larger campus impacts in retention and graduation.

The STEM Center's Logic Model (see Figure 1) was developed by thinking about each category, but not linearly. The visual shows a linear intervention from theories taken from literature and assumptions about our unique student population, to the resources 


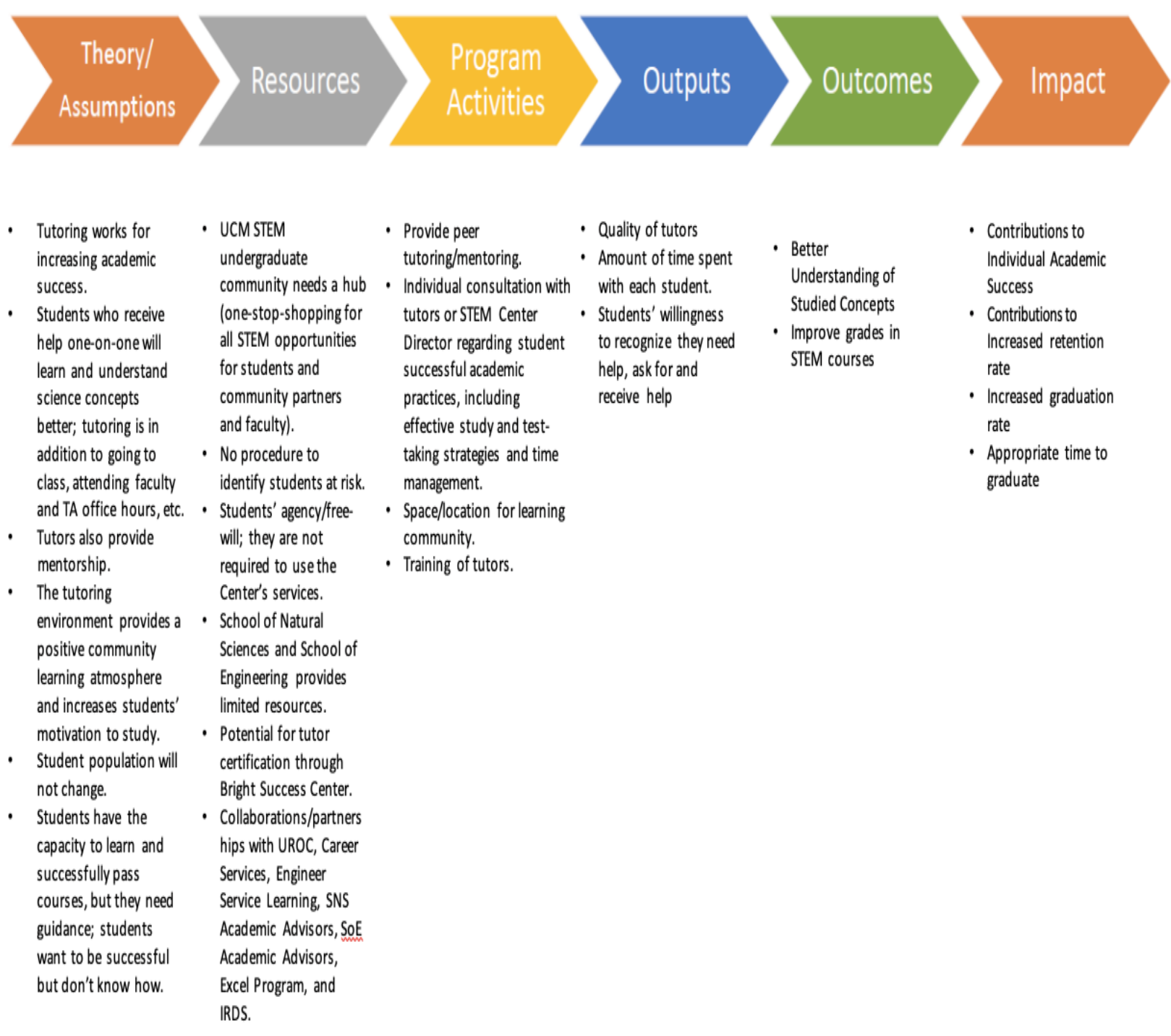

Figure 1. Logic Model: academic success of STEM Center students

or "inputs" that the campus has committed to activities, to the actual program activities and results from those activities. The results are separated between outputs, such as counting the number of student hours of tutoring and student learning outcomes - what content knowledge was actually learned and retained by the student because they worked with a tutor.

For outputs the guiding question is: Did the right people participate in the right numbers?

For outcomes the guiding question is: Did participants demonstrably learn what was intended?

Lastly, the impact is how this one set of small activities might contribute (but is not solely responsible) for larger campus measures such as retention and graduate rates and appropriate time to graduate.
Our unique approach is to place the assessment cycle on top of the outputs and outcomes. Student learning assessment has its own methodology, where we look at outputs and outcomes simultaneously. Such technique connects the logic model approach from the nonprofit section to how we think about student learning achievements in the aggregate in higher education as assessment tracks learning as a developmental process but provides us with a continuous self-reflexive basis for improvement. The following is using the STEM Center as an example of this type of results-driven look at student learning in higher education. 


\section{Outcomes and impact on student participants}

\subsection{Academic support for undergraduate students}

One of the main STEM Center goals is to provide academic support for undergraduate student for math, science and engineering courses in order to contribute to increasing UC Merced retention rates in the STEM disciplines. The STEM Center provides a location for a learning community of students to gather and collaborate on schoolwork and projects. Since its opening in Fall 2013, the center observes that the amount of student using the room steadily increases by an average of nine percent per semester. Currently, we serve about 310 individual students who use the location on regular basis throughout the semester. Of these students, typically, 65 percent are math and science majors, 30 percent are engineering majors, and 5 percent are non-STEM majors.

The STEM Center's Peer-Tutor/Mentor Program supports student learning and provides peer-tutoring assistance for math, science and engineering classes. Peer-tutors/mentors are selected based of their exceptional academic achievements, robust work ethics and excellent communication skills. These students have a strong dedication to the STEM Center's mission of aiding the UC Merced undergraduate community and serve as role models for their peers. Peer-tutors/mentors volunteer their time, unless a grant funding is obtained to provide stipends. An average of twenty students per semester provide 35 hours of tutoring per week for a range of math, chemistry, physics, biology, engineering, and computer science courses. A desired outcome is observed every semester, where above 80 percent of students using our services self-report that they are satisfied or highly satisfied with quality of tutoring and the use of the STEM Center.

In an effort to assess the STEM Center's contributions to the retention rates in the STEM disciplines, we evaluated the academic performance of students who regularly attended (around eight or more visits per semester) the STEM Center. With the assistance of the SNS Assessment Manager, the STEM Center administered surveys and further analyzed the survey data. We understand that our analysis has limitations, a major one being our small sample of students coming from various STEM majors and class levels, which makes establishing a control group very challenging. In order to create a more focused data analysis, we looked at final grade data sets for chemistry courses. Chemistry is one of the subjects most studied for at the STEM Center, therefore the General Chemistry I final grades were analyzed for Fall 2015 semester. Grades of students who received STEM Center services were compared to the rest of the students in this Chemistry course. The Wilcoxon-Mann-Whitney test suggests that there is a statistically significant different between the distributions of grades of students who went to the STEM Center and those who did not $(\mathrm{z}=2.403$, $\mathrm{p}=0.0162$ ).

Highly satisfactory service outcomes are also observed in respect to the overall Grade Point Average (GPA) for a selected group of students participating in the National Science Foundation (NSF) funded Math and Physical Sciences Program (MAPS) led by the STEM Center. In the span of six years, 90 percent (50 students) of MAPS scholars successfully completed the program. MAPS scholars continuously demonstrated better academic standing (GPA 3.1 vs. 2.6 out of a total of $4.0 \mathrm{GPA}$ ) and higher retention rates ( $82 \%$ vs. $67 \%$ ) compared to the control group consisting of students with similar backgrounds not enrolled in the program.

Another important outcome of the STEM Center's goals is related to the peer-tutors/mentors professional development. While serving their peers, our tutors/mentors gain work experience, further understand the dynamic of STEM academic communities and develop further develop their teamwork, leadership and communication skills. With the purpose of increasing their understanding of diversity sensitivity in academia and best practices and behaviors in working with peers, the STEM Center offers the Peer-Tutors/Mentors Professional Development Workshop Series. Assessment in this area demonstrates very desirable outcomes. The 2018-19 Survey results show that 100 percent (16 students) of peer-tutors/mentors agree that their skills in working with a diverse group of peers increased, with 63 percent self-reporting "much stronger" and 37 percent reporting a "stronger" increase. All students also self-reported growth in communication abilities, with 70 percent "much stronger" and 30 percent "stronger."

\subsection{Undergraduate research and fellowship opportunities}

A major goal of the STEM Center is to introduce undergraduate students to the importance of undergraduate research and to specific fellowship opportunities. The STEM Center uses presentations, one-on-one consultations, and support for UC Merced fellowship programs to help students understand the significance of strong academics and undergraduate research involvement, and to obtain scholarships, fellowships and internship positions. The majority of the students who visit the STEM Center require assistance to uncover research opportunities they might get involved into. As an outcome, 100 percent of the students self-report that they understand what options are available for them 
and an average of 80 percent of them uncover research opportunities that meet their specific interest. Additionally, individual consultations help students navigate the process and prepare a successful application. As a result, up-to-date, an average of 50 percent (280/560) students were placed in fellowship programs at UC Merced or obtained summer research positions in academia (among them, UC Berkeley, UC Los Angeles, UC Santa Barbara, UC San Diego, Harvard) or National Labs (Lawrence Livermore, Sandia). It is important to note that in assisting students to obtain an undergraduate research position, selection bias is a limitation to the data. Each student is evaluated based on their academic progress and conceptual knowledge, which are required to prepare a competitive application. In some cases, the STEM Center staff works with students to draft a plan for improving academic performance before moving on to securing a research position.

Via collaborative work with faculty and administrators, the STEM Center supports UC Merced federally-funded Undergraduate Fellowship Programs. The Center for Cellular and Biomolecular Machines (CCBM) was established in Summer 2016 with the National Science Foundation (NSF) support and focuses on multidisciplinary research in the areas of physics, chemistry, biology, material science, and bioengineering. CCBM's Scholars Undergraduate Research Fellowship is a part of the center and provides research and professional development experiences to eligible UC Merced and off-campus students. A total of 43 UC Merced students participated in the CREST Scholarship Program in the span of three academic years. The summer component of the fellowship supported a total of 29 students visiting from colleges such as Merced College, CSU Stanislaus, UC Irvine, and University of Florida.

The Merced nAnomaterials Center for Energy and Sensing (MACES) was launched in Summer 2015 with the support from the National Aeronautics and Space Administration (NASA), as a research and education center, focused on energy and sensing for space applications. As a part of MACES education activities, the Undergraduate Research Fellowship Program was established to provide training and professional development opportunities for students, specifically aiming at groups traditionally underrepresented in the STEM field. In order to enhance students' conceptual and interdisciplinary knowledge, the program integrates research experience, mentoring and workshops on topics ranging from presentation skills to career preparation. The program offers opportunities not only to UC Merced students, but also to those in local community colleges and in the nearby campuses of the California State University (CSU) system. In the span of four years, a total of 75 UC
Merced and 25 non -UC Merced students participated in the program; more than half of these students were from underrepresented groups. The program is evaluated yearly and data typically demonstrates 100 percent overall satisfaction [13]. Figure 2 represents findings for the Summer 2018 student cohort of students $(\mathrm{N}=7)$. Students report that MACES program enhanced their learning and intellectual development. All students agree that MACES increased their STEM knowledge and, an average, 86 percent of the students agree that MACES increased their confidence and STEMrelated abilities [14].

\begin{tabular}{|c|c|c|}
\hline $43 \%$ & \multicolumn{2}{|l|}{$57 \%$} \\
\hline \multicolumn{3}{|c|}{ MACES has helped you develop critical thinking skills } \\
\hline $57 \%$ & $29 \%$ & $14 \%$ \\
\hline \multicolumn{3}{|c|}{ MACES has increasedyour confidence in your abilities } \\
\hline $43 \%$ & $43 \%$ & $14 \%$ \\
\hline \multicolumn{3}{|c|}{ Your student mentor/research advisor is available for help } \\
\hline $43 \%$ & $43 \%$ & $14 \%$ \\
\hline Strongly Agree & \multirow{2}{*}{\multicolumn{2}{|c|}{$\begin{array}{l}\text { Neither Disagree Nor Agree } \\
\text { isagree }\end{array}$}} \\
\hline Disagree & & \\
\hline
\end{tabular}

Figure 2. MACES's impact on students' intellectual development and STEM knowledge

\subsection{K - 12 STEM Outreach}

The STEM Resource Center is committed to building a strong connection with the wider Central Valley communities, such as higher education institutions, local schools and organizations interested in the STEM field. Successful partnerships led to the implementation of a broad range of STEM demonstrations and hands on activities, mainly targeting K - 12 schools. Since Fall 2014, the STEM Resource Center participated in the design and implementation of seven major K-12 outreach initiatives: three offered to high school audience (MACES Outreach Program; CCBM - Science and Technology Enrichment Program, GirlCode Workshop), three offered to elementary/middle school students (Young Engineer and Scientist Academy, Mother-Daughter Science Camp, SWEET Academy) and one targeting 6-12 grade students (Expanding Your Horizon Conference). Led by STEM Center's staff, UC Merced undergraduate and graduate students were present at four high schools and seven elementary/K-8 schools in Merced, 
Madera and Fresno Counties. During these visits, we reached out to 1150 high school and 790 elementary/middle schools students. For all on- and off-campus events, University of California policy for working with minors is followed and UC Merced students volunteering at each event are instructed on the administrative and ethical aspects of such work. The STEM Center's assessment goal here was to have 80 percent of the $\mathrm{K}-12$ students self-report being satisfied with the activity they participate in. Results demonstrate that this benchmark is surpassed, with above 90 percent of the students reporting such satisfaction. Additionally, results show that STEM Center-led outreach activities increase K -12 students' knowledge and interest in the STEM field. For example, a survey administered to 40 high school students attending a MACES-led trip to NASA Ames Research Center shows that attending the trip significantly increased student's interest in STEM and NASA careers [15]. Of all attendees, 82 percent report increased interest in a career in the STEM field and 83 percent report increased interest in NASA careers (Figure 3 ).

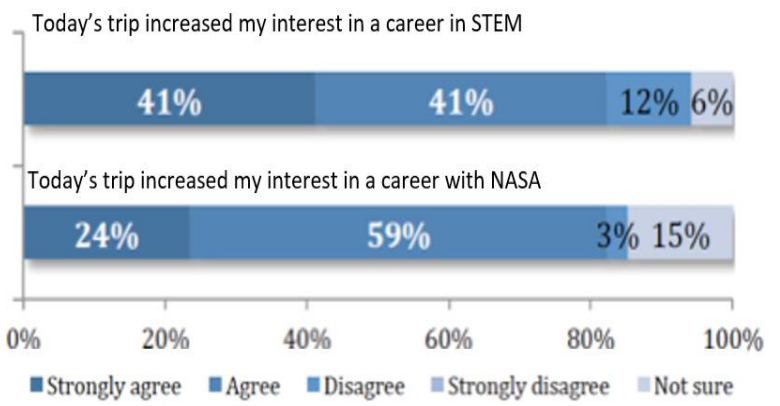

Figure 3. High school students: increasing interest in STEM and NASA careers

\subsection{Grants and external funding opportunities}

The STEM Center demonstrates excellent performance related to obtaining external funding with the purpose of increasing peer academic support and provide research fellowships for undergraduate students. Since Fall 2014, the STEM Center led the submission of proposals or provided extensive support to faculty on grant writing. As a result, it contributed to obtaining five successful grants, through which it supported peer-tutor payment and professional development, student-worker salaries, and undergraduate research fellowships. In the span of four years, from AY 2015-16 to AY 2018-19, the STEM Resource Center contributed to bringing a total of $\$ 1,131,000$ in external finding from funding resources such as NASA, the National Science Foundation, and UC Office of the President. Of them, approximately $\$ 31,000$ were used for peer- tutors/mentors hire, $\$ 2,000$ were used for studentworkers hire, and $\$ 1,098,000$ were distributed as undergraduate fellowships. Overall, the external funding aided the STEM Center to increase its number of peer-tutor/mentor hours, provide trainings for peer-tutors/mentors and place a larger number of undergraduate students at research labs.

\section{Conclusion}

In conclusion, our work demonstrates that wellstructured academic and extra-curricular support contributes to students' conceptual learning and enhances undergraduate research and professional development experiences. Combining our assessment plan with a logic model improved our continuous improvement processes and helped us create a strategic evaluation of the STEM Center. Via carefully planned efforts in providing peertutoring/mentoring assistance and undergraduate research support to UC Merced and programs and individual students, the STEM Center impacts their success and helps them achieve meaningful results. Leading K-12 outreach initiatives contributes to building a strong connection between UC Merced and the wider California Central Valley communities and ultimately contributes to college acceptance, retention and graduation.

\section{References}

[1] PolicyLink, (2013) 'California Unincorporated: Mapping Disadvantaged Communities in the San Joaquin Valley'http://www.policylink.org/sites/default/files/CA\%2 OUNINCORPORATED_FINAL.pdf

[2] Institutional Research and Decision Support (IRDS), (2018) 'Student Data' UC Merced; https://irds.ucmerced .edu/student-data

[3] National Center for Science and Engineering Statistics, National Science Foundation, (2018) 'Women, Minorities, and Persons with Disabilities in Science and Engineering' https://www.nsf.gov/statistics/2017/nsf17310/

[4] Santiago, D.A (2018) 'Excelencia in Education: What works for Latino student success in higher education' https://www.edexcelencia.org/research/publications/2018what-works-latino-students-higher-education

[5] Teitelbaum, M. S. (2014) Falling Behind? Boom, Bust and the Global Race for Scientific Talent, Princeton University Press, Princeton, USA.

[6] Mumford, K., S. Hill, and L. Kieffer; (2017) 'Utilizing Undergraduate Research to Enhance Integrative Learning', Council on Undergraduate Research Quarterly, v37 n4 (20170601): pp. 28-32.

[7] Munroe, D. (2016) 'Interdisciplinary CommunityConnected Capstone Courses: A Model for Engaging Undergraduates with Public Policy', Council on 
Undergraduate Research Quarterly 36(3): pp. 11-20. doi: $10.18833 /$ curq/36/3/2.

[8] Yang D., Xu, D., Yeh J. and Y. Fan (2019) 'Undergraduate Research Experience in Cybersecurity for Underrepresented Students and Students with Limited Research Opportunities', Journal of STEM Education: Innovation and Research, Vol 19, No 5, pp. 14-25.

[9] Eagan, M. K., Sharkness, J., Hurtado, S., Mosqueda, C. and Chang, M. J. (2011) 'Engaging undergraduates in science research: Not just about faculty willingness', Research in Higher Education 52, pp. 151-177.

[10] Bianchini, J. A. (2013) 'Expanding underrepresented minority participation: America's science and technology talent at the crossroads', Science Education 97, pp. 163166, doi:10.1002/sce.21032.

[11] Lopatto, D. (2003) 'The essential features of undergraduate research', Council on Undergraduate Research Quarterly 2, pp. 139-142.

[12] W.K. Kellogg Foundation (1998) 'Logic Model Development Guide: Using Logic Models to Bring Together Planning, evaluation and Action' https://ag.purdue.edu/extension/pdehs/Documents/Pub366 9.pdf

[13] Chang, M. and Krajcovicova, E. (2017) 'Year 2 External Evaluation Report, MACES', Mariko Chang Consulting, Inc, available upon request.

[14] Chang, M., Krajcovicova, E. and Boucher, M. (2018) 'External Evaluation Memo, MACES', Mariko Chang Consulting, Inc, available upon request.

[15] Chang, M. (2018) 'NASA High School Trip Evaluation Memo, MACES', Mariko Chang Consulting, Inc, available upon request.

\section{Acknowledgements}

The authors would like to thank the MACES and CCBM faculty and leadership, the Undergraduate Research Opportunity Center, the SNS Student Success Unit, and SATAL Services for their support in extracurricular and administrative aspects of this work. 